\title{
Neural Network Approach in Assessment of Fiber Concrete Impact Strength
}

\author{
Yasin Ansari $^{*}$, Seyed Amir Hossein Hashemi² \\ 1 Department of Construction Management, Qazvin Branch, Islamic Azad University, Qazvin, Iran \\ ${ }^{2}$ Department of Civil Engineering, Qazvin Branch, Islamic Azad University, Qazvin, Iran
}

*Correspondence should be addressed to Yasin Ansari, Department of Construction Management, Qazvin Branch, Islamic Azad University, Qazvin, Iran; Tell: +989121255688; Fax: +9877196187; Email: yasin.ansari@qiau.ac.ir.

\begin{abstract}
Use of neural network approaches in order to estimate mechanical and characteristics of concrete are common, in this regard, after making concrete samples in a laboratory the results of the laboratory are estimated by neural network. A drop impact test is used in order to evaluate impact strength of concrete samples; data obtained from the test usually has high dispersion. Various researches have been conducted to evaluate impact strength of concrete samples but no effort has made yet to predict impact strength of concrete by compressive, flexural strength. In the research, using neural network approach of ANN the impact strength of concrete is predicted from mixture design, compressive and flexural strength. In this regard, a numerical relation and range between compressive, flexural and impact strength have been predicted by collecting laboratory data from previous researches. Results for using neural network to estimate the compressive and flexural strength of concrete has shown that using this tool for estimating compressive and flexural strength of concrete is appropriate because the correlation coefficient between the estimated data and the laboratory data is near to 1 .

Key words: Neural network, Impact strength, Compressive, Flexural strength.

Copyright (c) 2017 Amir Hossein Hashemi et al. This is an open access paper distributed under the Creative Commons Attribution License. Journal of Civil Engineering and Materials Application is published by Lexis Publisher; Journal p-ISSN xxxx-xxxx; Journal e-ISSN 2588-2880.
\end{abstract}

\section{INTRODUCTION}

I mpact strength is a criterion for the hardness of a material which is defined as an ability of polymer or polymeric composite material to withstand a sudden applied energy. ACI and various concrete regulations have suggested drop hammer test for evaluating impact strength of fiber concretes. This test has been used in papers due to simplicity and cheapness. Data obtained from this test mostly has high dispersion so that coefficient of variation among various data is higher than $29 \&$. Using statistics is common for estimating correlation coefficient in compressive strength and concrete impact strength data so that most of available statistical data obtained from the drop hammer test are about fiber concretes. In this regard, many researchers have conducted research on impact strength of concrete with its mechanical characteristics in laboratory. For example, Ong et al. (1) indicate more energy absorption of concrete slabs reinforced by steel fiber with hooked ending comparing to slabs reinforced by fiber of polypropylene and polyvinyl alcohol against impact caused by low velocity projectiles. Zhang et al. (2) in their researches on depth of penetration of impacts on high strength concretes found that the more strength of concrete, the less depth of penetration of impacts. Schleyer et al. (3) studied behavior of high strength fiber reinforced concretes against explosion and concluded that this type of concretes has better performance than standard concretes. Maundens (200) has evaluated behavior of fiber concretes and their impact strengths, compressive strength of the built concretes has been between 60 MPA and 120 MPA, and results have shown variation of fibers in mixer can have a significant effect on increase or decrease in impact strength (4). Mastali et al. (2015) have evaluated behavior of compressive, tensile and impact strength of concrete samples. In the research, glass fibers as additive have been used in concrete, as well statistical methods have been evaluated in order to find the appropriate distribution of probability for compressive and flexural strength of concrete and also impact strength (5). Nikoui et al. (2015) have evaluated flexural and compressive behavior of fiber concretes of PPS and their strength against impact. In the research, probability distribution function have been drawn 
for compressive, flexural strength and the first crack on the concrete (6). Mohammadhosseini (2017) has evaluated effect of impact on carpet fiber concretes. In the research, drop impact test has been used in order to evaluate impact strength of concrete and slump, compressive and flexural strength test has been used for evaluating physical strength of concrete. Eventually, data dispersion has been drawn on probability distribution function and number of impacts that the first crack has occurred has been reported (7). Using the impact test on various concerts and steel fiber to evaluate behavior of structure is a common matter, for example, using the impact test in concretes made by metal fibers is a common matter so that beginning of these researches is related to loc in 1990 that evaluated physical behavior of samples made by metal fibers and their strength against impact (8). Khalil et al. have evaluated strength of concrete samples and the impact test. In the research, physical characteristics of concrete such as compressive, flexural and tensile strength of have been studied and value of correlation and number of impacts with compressive strength have been obtained (9). Hrynyk (2014) has evaluated behavior of concrete samples made by metal fibers and the effect of impact on them. In the research, value of compressive, flexural and tensile strength of concrete has been evaluated as well and eventually continuity between compressive strength and impact strength of concrete was evaluated (10). In the present research, relation between compressive, flexural strength and impact strength of fiber concretes will be evaluated using data existing in the previous researches. In order to achieve this important issue it is attempted to first introduce the solving methods and parameters of the variable to create the neural network model; then to measure the power of the made model in estimating value of impact strength of concrete. It seems that considering high dispersion of the data obtained from the impact test, using neural network approaches can be an effective help to conclude results of impact strength of fiber concretes and play a useful role in creating the relationship between compressive and flexural strength of concrete and also impact strength.

\section{PREPARATION OF DATA OF THE RESEARCH}

Test of compressive, flexural strength and impact strength of fiber concrete in the previous researches has been used in order to evaluate data and to estimate the results. In this regard, it has been attempted to use researches that a perfect set of statistical data in all experiments and also number of impacts and the first crack created in concrete is specified. Results of researches of Mastali et al. Nikoui and Mohammadhosseini has been used to make the neural network. Common tests in the researches are as following.

\subsection{Impact test}

to conduct this test, the test sample is placed inside the holder and then the hammer is released by rotating the magnet locker and eventually the samples are hit and after breaking the sample, the hammer goes up to a certain height. The initial and final angles are displayed by the impact software in a computer monitor. Also, the software is able to calculate friction, fracture energy, primary energy and secondary energy (8).

\subsection{Compressive strength test}

Compressive strength includes the bearing capacity of an object, building materials or structure against direct axial compressive forces so that when the compressive strength limit of a material occurs, the material will be destroyed. Concrete is a material with high compressive strength; for example, the concrete used in many concrete structures has the ability to bear compressions higher than 50 megapascal; this is while soft materials such as soft sandstone have a compressive strength about 5 or 10 megapascal (9). In order to evaluate capability of the neural network and predict impact strength of concrete, range of compressive strength, strength of the first crack, the final crack have been obtained from the previous researches in various percentages of adding fiber and after averaging, the relationship between the parameters has been evaluated and the impact strength has been predicted. Table 1 shows a summary of laboratory information for the concrete mixture design made of fibers that will be entered the neural network after conducting experimental tests. 
Table 1. Mixture design and values of materials used in fiber concrete

\begin{tabular}{|c|c|c|c|c|c|c|}
\hline Researcher & Mix number & water/cement & Cement & Fiber & Fine aggregate & $S P$ \\
\hline \multirow[t]{3}{*}{ M.Mastali et al } & 2 & 0.34 & 940 & 7 & 940 & 3.4 \\
\hline & 3 & 0.34 & 940 & 21 & 940 & 3.4 \\
\hline & 4 & 0.34 & 940 & 35 & 940 & 3.4 \\
\hline \multirow[t]{3}{*}{ Nekoyi et al } & 5 & 0.44 & 375 & 0 & 980 & 3.9 \\
\hline & 6 & 0.44 & 348 & 26 & 980 & 3.9 \\
\hline & 7 & 0.44 & 322 & 53 & 980 & 3.9 \\
\hline \multirow[t]{12}{*}{ Mohammad et al } & 8 & 0.47 & 455 & 0 & 840 & 0 \\
\hline & 9 & 0.47 & 455 & 0 & 840 & 0 \\
\hline & 10 & 0.47 & 455 & 0 & 840 & 0 \\
\hline & 11 & 0.47 & 455 & 0 & 840 & 0 \\
\hline & 12 & 0.47 & 455 & 0 & 840 & 0 \\
\hline & 13 & 0.47 & 455 & 0 & 840 & 0 \\
\hline & 14 & 0.59 & 364 & 91 & 840 & 0 \\
\hline & 15 & 0.59 & 364 & 91 & 840 & 0 \\
\hline & 16 & 0.59 & 364 & 91 & 840 & 0 \\
\hline & 17 & 0.59 & 364 & 91 & 840 & 0 \\
\hline & 18 & 0.59 & 364 & 91 & 840 & 0 \\
\hline & 19 & 0.59 & 364 & 91 & 840 & 0 \\
\hline
\end{tabular}

In the following, Table 2 shows the value of compressive strength, the impact strength of concrete during the formation of the first crack and the final strength of concrete samples. In all researches, adding fibers to concrete samples has led to increase in compressive and impact strength of concrete samples. Strengths reported in the researches are 28 days and the number of impacts for the strength of the first crack and the final strength has increased with increase in percentage of fiber. The relationship between compressive strength, selective mixture designs and hammer number for the first crack and the final crack has been evaluated in the present research. For this purpose, parameters in Table 1 have been considered as input and parameters in Table 2 have been considered as output and after that, the intended neural network was made.

Table 2. Average of compressive strength and parameters of impact strength in various researches

\begin{tabular}{|c|c|c|c|c|c|}
\hline Row & Number of samples & Compressive strength & Flexural strength & $F C$ & $U C$ \\
\hline 1 & 20 & 50.21 & 4 & 38.07 & 47.07 \\
\hline 2 & 20 & 55.83 & 5.1 & 55.97 & 71.07 \\
\hline 3 & 20 & 59.17 & 6.1 & 75.97 & 98.32 \\
\hline 4 & 20 & 57.47 & 4.41 & 56.9 & 19.6 \\
\hline 5 & 20 & 61.51 & 5.45 & 38.97 & 46.97 \\
\hline 6 & 20 & 65.32 & 5.84 & 50.49 & 73.4 \\
\hline 7 & 20 & 47 & 4.45 & 24 & 28 \\
\hline 8 & 20 & 44.15 & 4.95 & 37 & 48 \\
\hline 9 & 20 & 43.45 & 5.55 & 62 & 81 \\
\hline 10 & 20 & 41.75 & 5.35 & 77 & 95 \\
\hline 11 & 20 & 38.5 & 4.95 & 96 & 117 \\
\hline 12 & 20 & 37.05 & 4.85 & 112 & 145 \\
\hline 13 & 20 & 42.2 & 4.15 & 19 & 22 \\
\hline 14 & 20 & 38.65 & 4.6 & 32 & 44 \\
\hline 15 & 20 & 36.35 & 5.15 & 55 & 73 \\
\hline 16 & 20 & 34 & 5.1 & 69 & 85 \\
\hline 17 & 20 & 32.25 & 4.75 & 90 & 111 \\
\hline 18 & 20 & 29.55 & 4.65 & 105 & 138 \\
\hline
\end{tabular}




\section{SOLVING METHOD}

Strength of concrete as one of the most important parameters required for design depends on many factors such as concrete mixture design, genus of materials forming concrete, laboratory conditions, tester's abilities, laboratory errors and etc. Since many of these factors are unknown and no certain and relatively accurate formulation for concrete can be found, so using a method which can predict strength of concrete beyond the usual mathematical formulas will be important. Nowadays, using neural networks inspired by the behavior of brain and neurons in problems that naturally have many passives and in some cases makes access to their solution impossible is increasing. In the first part of the research with the results of a large number of laboratory samples (including percentages of components of the sample and strength of the intended sample), a three-layer neural network, will be trained with error post-release learning algorithm using linear and sigmoid transfer functions in the middle and output layers. After this test, the network will have the capability to predict compressive strength of a cubic meter of concrete by weights of components of that.

\section{MAKING NEURAL NETWORK MODEL}

The neural network used in this paper is fed forward neural network, the mentioned network is capable to connect the output of each cell to next initial cells, so its performance is one-sided, because of this, it is called feed forward neural network. Using feed forward neural network in researches has been usual for predicting compressive strength of concrete, as well in this research by data entry to MATLAB software and conducting trial and error tests for many times; the results showed that using the mentioned neural network in predicting outputs can report favorable results. After using several networks in MATLAB software with data obtained from the test and considering suggestions existing in the other laboratory researches- the neural network has been considered related to fiber concrete, ANN neural network with three layers for available. Average of numbers related to 120 laboratory data that tests of compressive strength and impact have been repeated three times on them and have been entered MATLAB software as separated output layers and by repeating trial and error and sometimes training the network, outputs were predicted for several times and the results will be reported in following, Efficiency of the model for stages of training, validation and test has been evaluated by parameters of mean square error (MSE) and correlation coefficient of R (10). For this purpose, data have been divided into categories of training, validation and test and values of error and correlation coefficient have been obtained in three categories, low error value among the predicted data and laboratory values and also high correlation coefficient shows the fact that the mentioned neural network has been able to estimate the strength of concrete accurately.

\subsection{The Network Inputs}

The percentage of additive materials and their types in each sample of sand, gravel, water, steel fibers is other additive materials and the network output is compressive strength and impact strength of concrete. In this regard, in the same conditions, the tree made samples are averaged and entered MATLAB software as input. Figure 1 shows inputs required for making the neural network and along with it, the output considered for estimating strength data in MATLAB software. In this part after sorting data from previous studies, the whole data are sorted based on cement, water-to-cement ratio, the percentage of aggregate, the percentage of fine aggregate and other additive materials (fiber). Then, inputs are entered the software and the intended outputs including compressive strength and value of concrete impact strength in the first crack and the final crack are estimated and eventually, the values estimated for compressive strength and number of impacts in initial and final cracks are drawn and the correlation coefficient among that is calculated. 


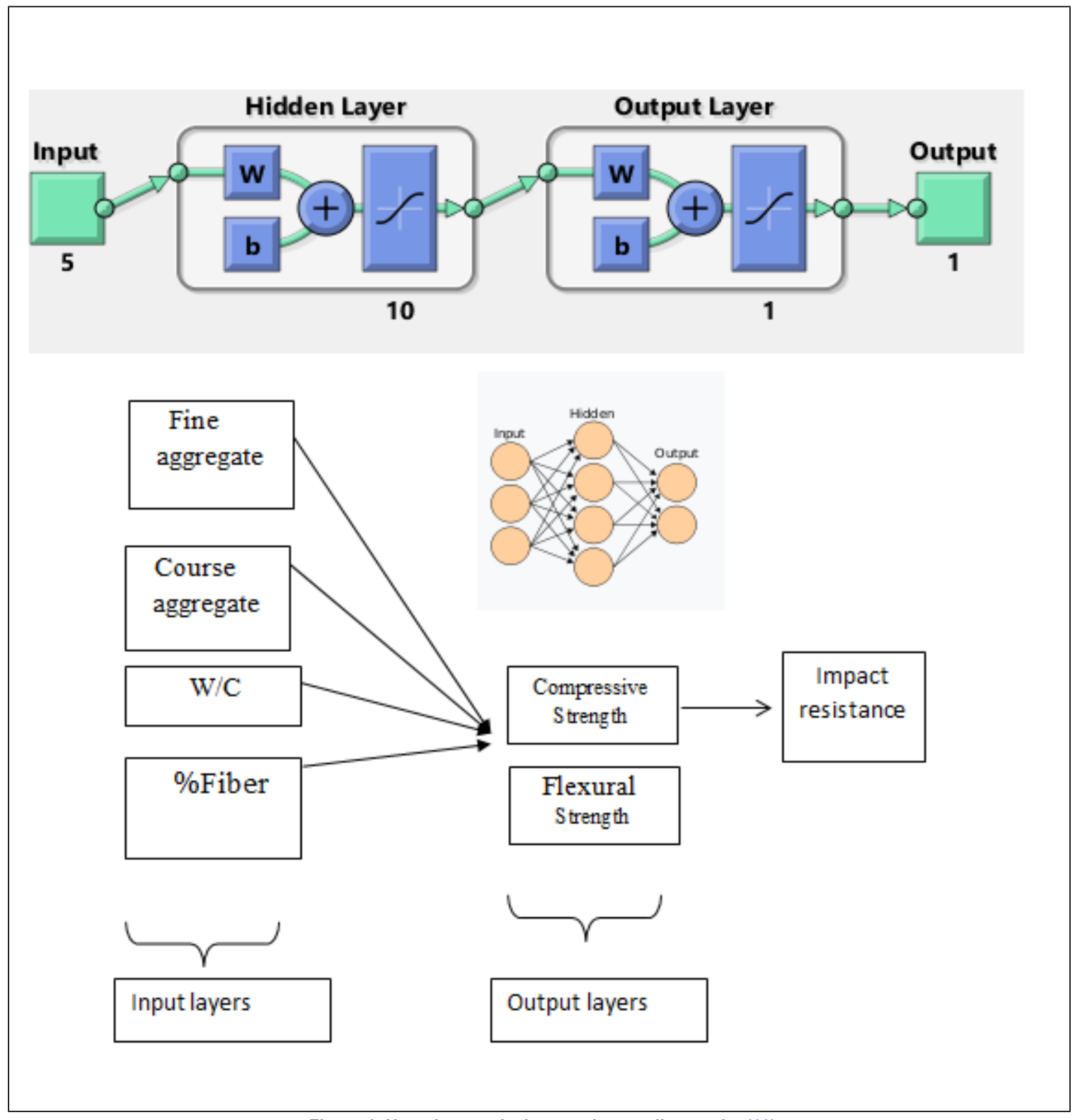

Figure 1. Neural network view used to predict results (10)

\section{RESULTS}

Figure 2 shows the correlation coefficient obtained from the laboratory samples and estimated values for the compressive strength. As it is clear in the figure, the correlation coefficient for the compressive strength of concrete in training data, test data and validation data is, respectively, 0.90, 0.98 and 0.96. Also, using this method has managed to predict all data with estimation of 0.90 that shows an important issue that the estimated values are very near to the laboratory values and an insignificant difference has observed in data which had been left out to evaluate and validate the results and using the equation of the mentioned lines the values in the laboratory can be predicted with a relatively good approximation. Actually, the obtained values are $\mathrm{Y}$ (predicted values), values of $\mathrm{X}$ (laboratory) can be obtained with the relevant line equation. 


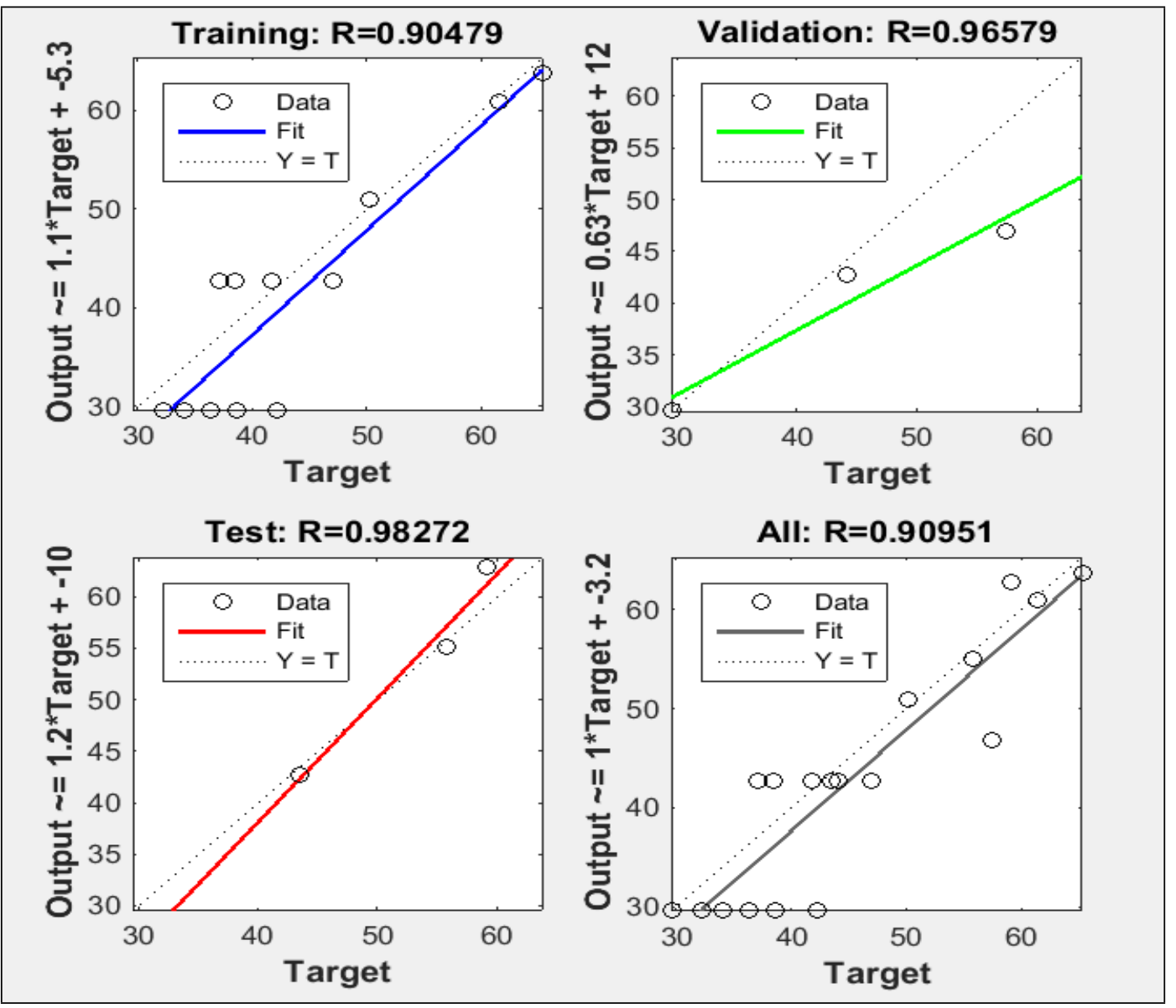

Figure 2. A summary of the results obtained from MATLAB to estimate the compressive strength

In the following, Figure 3 shows results for use of the neural network for estimating the flexural strength and the laboratory results of concrete. The correlation coefficient for the compressive strength of concrete in training data, test data and validation data is, respectively, 0.90, 0.94 and
0.99. Also, using this method has managed to predict all data with estimation of 0.94 that shows an important issue that the estimated values are very near to the laboratory values. 

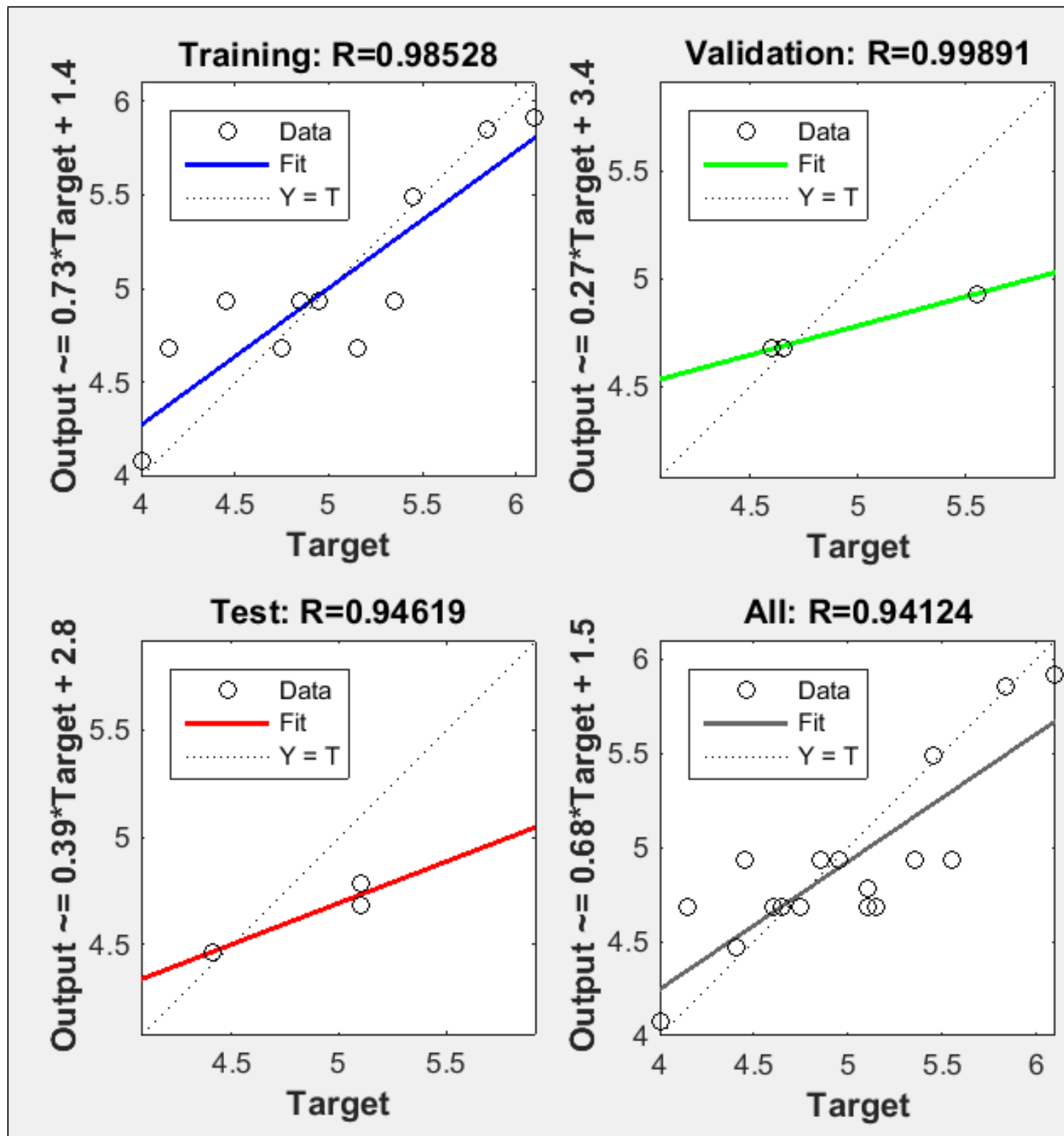

Figure 3. A summary of results obtained from MATLAB to estimate the flexural strength

The obtained results in various mixture designs have been analyzed by the neural network and MATLAB software. Results have shown the value of the compressive strength can be estimated using the mixture design. Concerning estimation of the weight energy and the number of impacts to create the initial and final cracks, all numbers were entered excel software and a good correlation relationship exists between compressive strength and number of impacts for creating the initial crack and also the final crack. Figure 4 shows the ration ship between compressive strength and FC as impact rebound. 


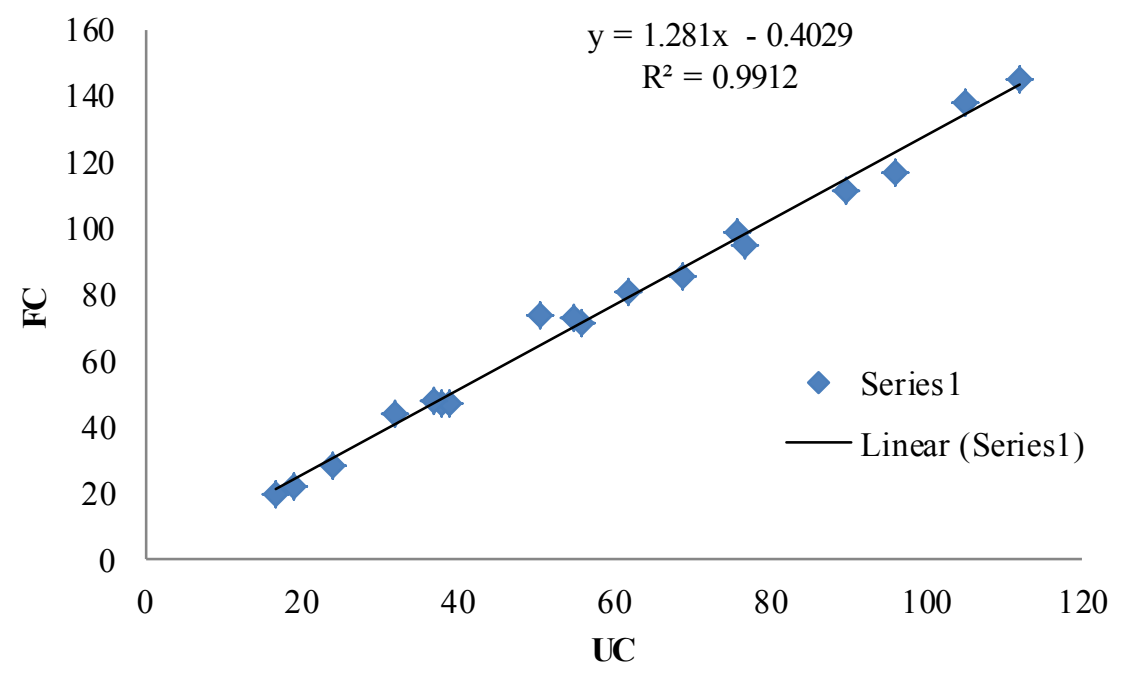

Figure 4. Correlation coefficient between the first crack because of throwing impact and the final crack in all researches

In the following, Figure 5 shows the correlation coefficient between the compressive strength and number of impacts required for creating the initial crack and the final crack of the hammer. As it is clear in all researches, there has been a good correlation coefficient between the compressive strength and number of hammer impacts in various researches. So, using the mixture design it is suggested to estimate the compressive strength of fiber concretes in various researches and to obtain the number of impacts required for creating the initial and final cracks from relations existing in the researches. Using impact test tool in data of the research in the standard condition had led to the ability to obtain the number of hammer impacts through the specific mixture design.
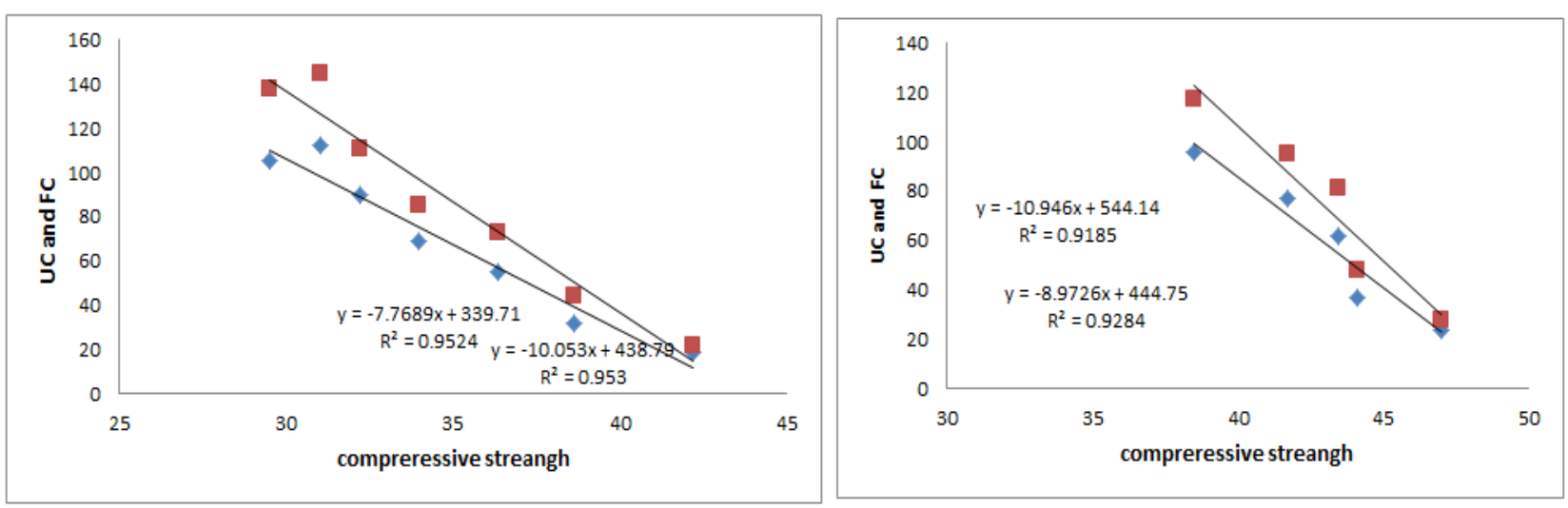

Figure 5. Correlation coefficient between the first crack created by throwing impact and the compressive strength in the researches

\section{PREDICTION OF RESULTS}

In following in order to evaluate the results, a table has been provided that by determining the mixture design the values of the compressive strength, impact strength and number of impact for creating the first crack can be estimated and the goal to regulate the table has been estimation of the compressive strength of concrete. In the table it has been tried to enter the inputs of the neural network in three samples, a sample has been taken from the previous researches and in the suggested samples the value of water to cement has been considered variable and the power of the software to estimate the answer has been measured. The predicted values for the flexural strength have been reported in the last column. As it is observed, by reducing the made sample to the model, the model is able to evaluate the compressive strength and number of impact for creating the first crack and the final crack. Summary of the results as mentioned in Table 3 with the topic of the mixture design suggested by the paper out of the laboratory studies. As it is expected, by the increase of water-tocement ratio the compressive strength has reduced, the estimated values are consistent with the laboratory results. At the end of the research in order to evaluate the made network, mean square root error and mean error percentage in the made network have been evaluated and have been summarized with characteristics of the made network in Table 4 and Figure 5, Figure 6 and Figure 7. 


\begin{tabular}{c|cccccc}
\hline water/cement & Cement & Fiber & Fine aggregate & $S P$ & $\begin{array}{c}\text { Compressive } \\
\text { Strength }\end{array}$ & $N$ \\
\hline 0.34 & 580 & 0 & 800 & 3.4 & 53 & 38 \\
0.34 & 940 & 7 & 940 & 3.4 & 54 & 55 \\
0.34 & 940 & 7 & 940 & 3.4 & 55 & 58 \\
0.34 & 580 & 35 & 940 & 3.4 & 61 & 77 \\
0.44 & 375 & 0 & 980 & 3.9 & 65 & 96 \\
\hline
\end{tabular}

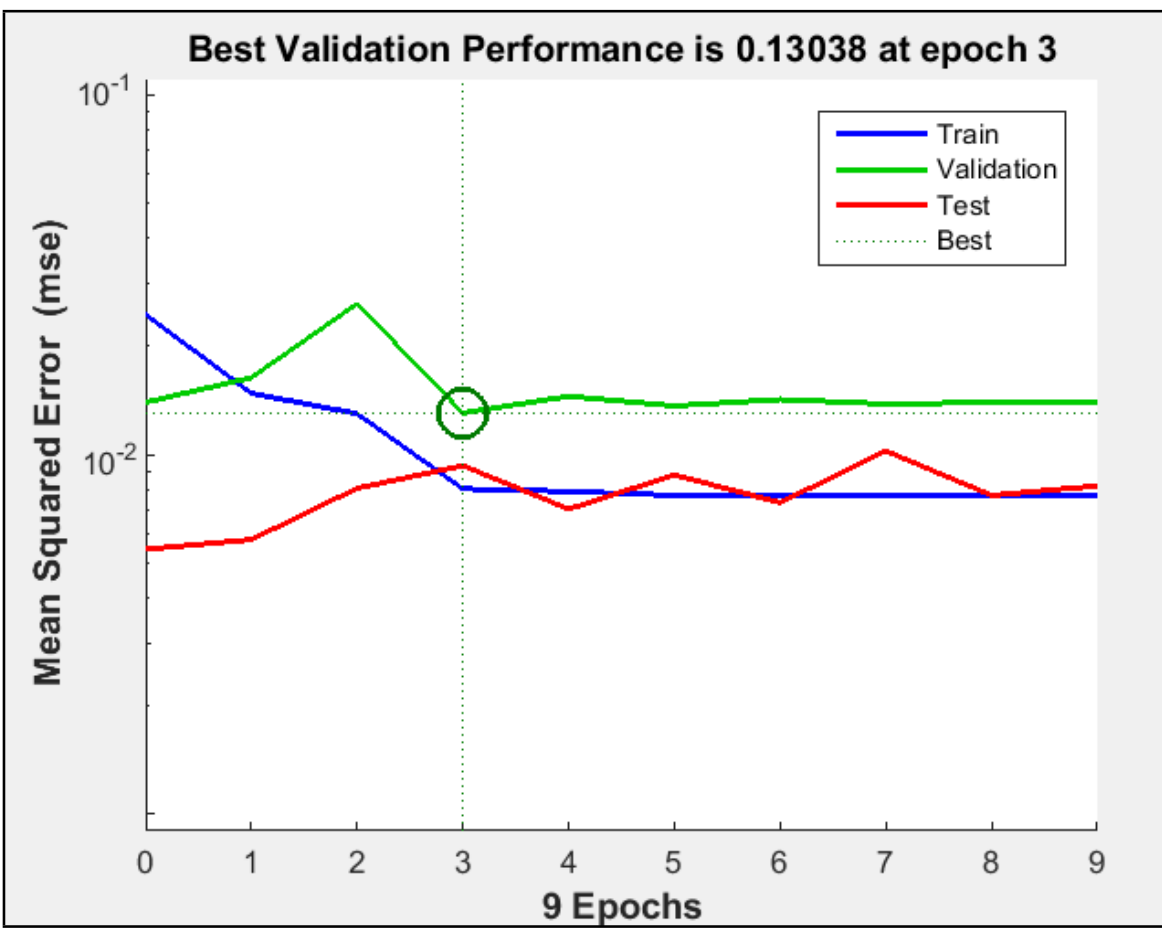

Figure 6. Variations of MSE against period for the compressive strength

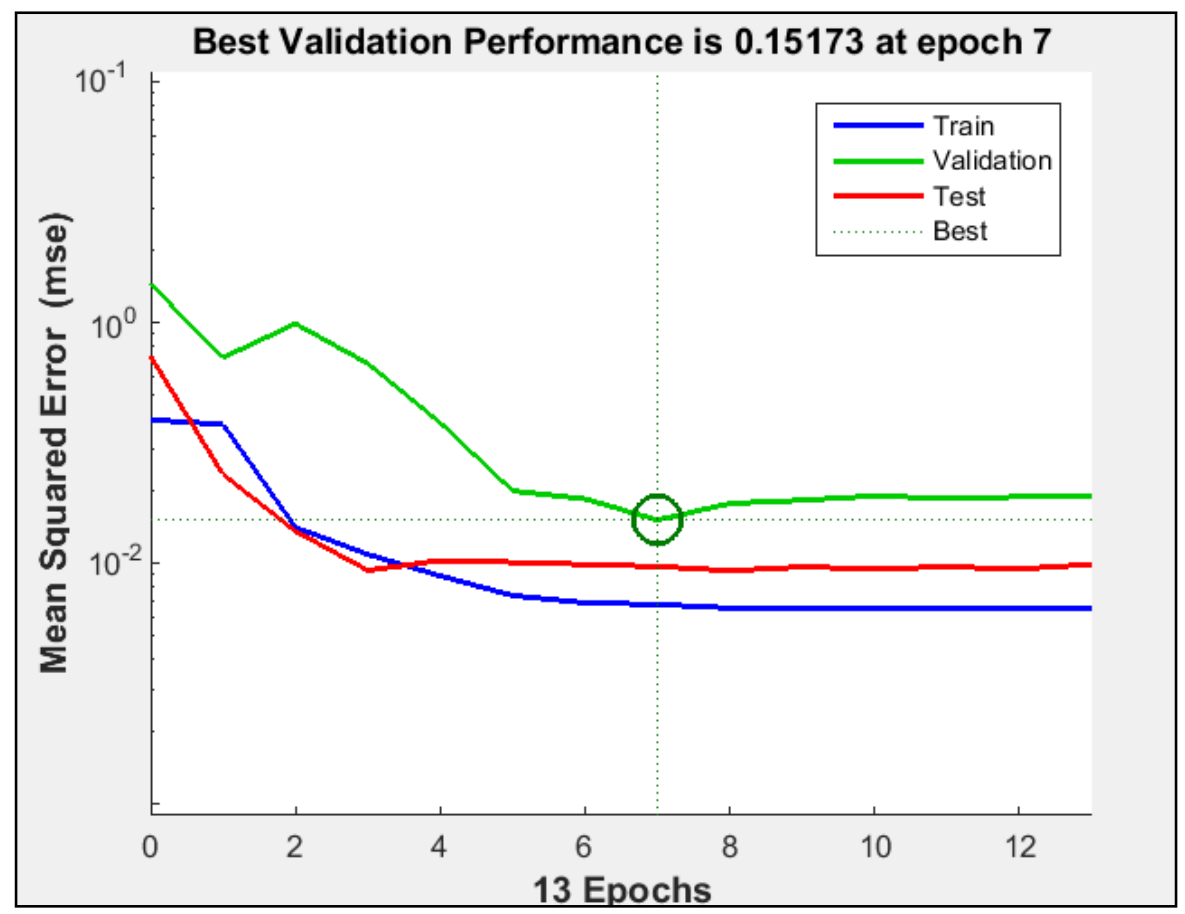

Figure 7. Variations of MSE against period for the flexural strength

The error of MSE in compressive and flexural strength is decreased with the increase in the number of epochs of the structure to 3 for the compressive strength and 7 for the flexural strength to reach 0.03 and 0.04 for the compressive and flexural strength in the least value. After that, by an increase in epochs the error value for test, training and validation data remains constant that shows an important issue that the mentioned network has been able 
to estimate the laboratory results in the leas error value with the highest value of R.

Table 4. Selected values for estimating the compressive strength and number of hammer impacts

\begin{tabular}{c|cccc}
\hline Neural network & Number of epochs & RMSE & MPE & $R$ \\
\hline Compressive strength & 7 & 0.03 & 0.0028 & 0.96 \\
Flexural strength & 8 & 0.04 & 0.003 & 0.94 \\
\hline
\end{tabular}

\section{CONCLUSION}

In the present research, the relationship between the compressive strength and the impact strength of concrete has been evaluated using the previous researches. Results of the research have shown that there is a significant relationship between the number of hammer impacts for creating the first crack, the final crack and the compressive strength of concrete. Increase in percentage of fibers in concrete has led to the growth of the compressive strength and also the hammer number. Numbers required for creating the first crack in the surface of fiber concretes had a correlation with the compressive strength of concrete and number of impacts required for the final cracks in the various researches. MATLAB software and ANN neural tool have managed to estimate number of the compressive strength in various mixture designs and considering the correlation between the compressive strength and the impacts created for the first crack and the final crack the value of the impact strength in each sample can be estimated in each research using the suggested mixture design and the compressive strength. Correlation between the compressive strengths estimated in various samples and number of required impacts for creating the first crack and the final crack are available in various researches and also among the number of created impacts on the concrete sample in creating the final crack and the initial crack the correlation among data has been observed in various researches.

\section{FUNDING/SUPPORT}

Not mentioned any Funding/Support by authors.

\section{ACKNOWLEDGMENT}

Not mentioned any acknowledgment by authors.

\section{AUTHORS CONTRIBUTION}

This work was carried out in collaboration among all authors.

\section{CONFLICT OF INTEREST}

The author (s) declared no potential conflicts of interests with respect to the authorship and/or publication of this paper.

\section{REFERENCES}

1. Ong K, Basheerkhan M, Paramasivam P. Resistance of fibre concrete slabs to low velocity projectile impact. Cement and Concrete Composites. 1999;21(5):391-401.

2. Zhang M, Shim V, Lu G, Chew C. Resistance of high-strength concrete to projectile impact. International Journal of Impact Engineering. 2005;31(7):825-41.

3. Barnett SJ, Lataste J-F, Parry T, Millard SG, Soutsos MN. Assessment of fibre orientation in ultra high performance fibre reinforced concrete and its effect on flexural strength. Materials and Structures. 2010;43(7):1009-23.

4. Mastali M, Dalvand A, Sattarifard A. The impact resistance and mechanical properties of reinforced self-compacting concrete with recycled glass fibre reinforced polymers. Journal of Cleaner Production. 2016;124:312-24.

5. Nikoui A, Dalvand A, Sharbatdar M, Kheyroddin A. Experimental and statistical investigation on mechanical properties and impact resistance of synthetic fiber reinforced concrete. Iranian Journal of Science and Technology Transactions of Civil Engineering. 2015;39:449-68.

6. Mohammadhosseini $\mathrm{H}$, Abdul Awal ASM, Mohd Yatim JB. The impact resistance and mechanical properties of concrete reinforced with waste polypropylene carpet fibres. Construction and Building Materials. 2017;143(Supplement C):147-57.

7. Lok T, Pei J. Impact resistance and ductility of steel fibre reinforced concrete panels. HKIE Transactions. 1996;3(3):7-16.

8. Mindess S, Zhang L. Impact resistance of fibre-reinforced concrete. Proceedings of the Institution of Civil Engineers-Structures and Buildings. 2009;162(1):69-76.

9. Khalil E, Abd-Elmohsen M, Anwar AM. Impact Resistance of Rubberized Self-Compacting Concrete. Water Science. 2015;29(1):45-53.

10. Hrynyk TD, Vecchio FJ. Behavior of steel fiber-reinforced concrete slabs under impact load. ACI structural journal. 2014;111(5):1213. 